\title{
Reliability Modelling and Analysis of the Power Take-Off System of an Oscillating Wave Surge Converter
}

\author{
Eetu Heikkilä *(D), Tero Välisalo, Risto Tiusanen, Janne Sarsama and Minna Räikkönen \\ VTT Technical Research Centre of Finland Ltd., Visiokatu 4, P.O. Box 1300, 33101 Tampere, Finland; \\ tero.valisalo@vtt.fi (T.V.); risto.tiusanen@vtt.fi (R.T.); janne.sarsama@vtt.fi (J.S.); minna.raikkonen@vtt.fi (M.R.) \\ * Correspondence: eetu.heikkila@vtt.fi; Tel.: +358-40-849-5790
}

Citation: Heikkilä, E.; Välisalo, T.; Tiusanen, R.; Sarsama, J.; Räikkönen, M. Reliability Modelling and Analysis of the Power Take-Off System of an Oscillating Wave Surge Converter. J. Mar. Sci. Eng. 2021, 9, 552. https:// doi.org/10.3390/jmse9050552

Academic Editor: Silvio Barbarelli

Received: 16 April 2021

Accepted: 19 May 2021

Published: 20 May 2021

Publisher's Note: MDPI stays neutral with regard to jurisdictional claims in published maps and institutional affiliations.

Copyright: (c) 2021 by the authors. Licensee MDPI, Basel, Switzerland. This article is an open access article distributed under the terms and conditions of the Creative Commons Attribution (CC BY) license (https:// creativecommons.org/licenses/by/ $4.0 /)$.

\begin{abstract}
Wave power is a potential technology for generating sustainable renewable energy. Several types of wave energy converters (WECs) have been proposed for this purpose. WECs operate in a harsh maritime environment that sets strict limitations on how and when the device can be economically and safely reached for maintenance. Thus, to ensure profitable energy generation over the system life cycle, system reliability is a key aspect to be considered in WEC development. In this article, we describe a reliability analysis approach for WEC development, based on the use of reliability block diagram (RBD) modelling. We apply the approach in a case study involving a submerged oscillating wave surge converter device concept that utilizes hydraulics in its power take-off system. In addition to describing the modelling approach, we discuss the data sources that were used for gathering reliability data for the components used in a novel system concept with very limited historical or experimental data available. This includes considerations of the data quality from various sources. As a result, we present examples of applying the RBD modelling approach in the context of WEC development and discuss the applicability of the approach in supporting the development of new technologies.
\end{abstract}

Keywords: wave energy; power take-off; reliability modelling; reliability analysis; reliability block diagram

\section{Introduction}

\subsection{Wave Energy and Reliability}

Ocean Energy Europe (OEE), one of the European Technology and Innovation Platforms (ETIPs), states that the oceans are the world's largest untapped source of renewable energy [1]. Oceans have energy in many forms, the main forms being waves, tides, marine currents, the salinity gradient, and the temperature gradient. Currently, the main exploitable forms of ocean energy are wave and tidal energy, and the related technologies are the most mature among ocean energy technologies [2]. The OEE states that wave energy has the potential to be the largest source of clean energy [3], and according to the European Commission Strategic Energy Technologies Information System (SETIS) [2], the estimated global potential of wave energy is $29,500 \mathrm{TWh} /$ year. In the same source, the estimated global tidal energy resource is mentioned as $1200 \mathrm{TWh} /$ year. Based on these figures, the global potential resource of wave energy compared with tidal energy is approximately 25 times greater.

However, compared with some other forms of renewable energy, such as wind and solar energy, wave energy technologies are-to a large extent-still at the research and development stage and not yet commercially available [4]. Over time, a wide variety of technologies have been developed for harnessing wave energy. For example, according to [2], as many as 170 different types of wave energy technologies, i.e., different wave energy converter (WEC) types, have been developed. Fewer than $20 \%$ of these are at the full-scale prototype stage [2]. There are many ways to classify the different WEC types, and there is no present standard classification for these $[2,5,6]$. 
One of the WEC types that has been developed to the level of full-scale applications is the Oscillating Wave Surge Converter (OWSC) that extracts energy from wave surges. The OWSC employs a mechanical element, such as a plate or a flap, that acts as a pendulum and oscillates with the waves [7]. OWSCs can be fully submerged, or part of the device can be on top of the water surface. In this paper, we focus on a proposed MegaRoller OWSC concept (see Section 1.2).

In WEC devices, the power take-off (PTO) is the subsystem that converts the mechanical energy captured from waves into electricity [8]. In PTO design, efficiency and reliability are key issues to be considered. This is partly due to the nature of the loads that the WEC faces: ocean waves generate slow oscillations that differ in magnitude. Thus, a WEC is required to withstand large alternating forces in order to remain functional and to produce electricity [9].

Electricity production needs to be efficient and reliable for the WEC to be profitable. The reliability of the WEC device is one the most important factors affecting life cycle costs and, eventually, the cost of the electricity produced. This is emphasized by the costs related to maintenance activities in the maritime setting. The importance of the reliability of WEC devices has been widely identified, and studies on the subject were already being published in the 1970s and 80s [10]. However, most WEC technologies have been designed more recently as the demand for renewable energy has increased. Thus, there is only a very limited amount of previous research available. Some of the available studies focus on the mechanical and hydrodynamic characteristics of WEC elements that are related to the energy capture from waves $[11,12]$ but not directly on the PTO. Some studies consider the survivability of WECs in extreme sea states such as storms [13] or even tsunamis [14].

Reliability studies that also include considerations of the PTO system have been performed by Ambühl [11], Cretu et al. [15], Mueller et al. [16] and Thies [17]. All these studies have examined WEC concepts with very different operational principles, all of which are also different from the MegaRoller device. In previous studies, both qualitative (e.g., failure mode and effects analysis) and quantitative (e.g., reliability block diagrams, Bayesian statistics) methods have been applied [18]. While the PTO can mostly consist of commercial off-the-shelf components, maritime operating conditions need to be considered in reliability studies [10]. In addition to technical reliability studies, McAuliffe et al. [19], Heikkilä et al. [20] and Tiusanen et al. [21] have published studies considering the linkage between economic profitability and the reliability of WEC technology. Reliability engineering should not be considered as a separate issue focusing on technical issues in systems engineering but rather as a process of interconnected efforts that complement each other and bring together technical, economic, operational and maintenance aspects [21].

The need for reliability data to perform system reliability analysis has been identified as a relevant issue in WEC design. As there is very limited experience of previous WEC installations, a combination of several data sources is needed to perform analysis. For example, a wave energy converter called Pelamis P2 has been the object of a case study concerning the reliability of a WEC [22]. In that case, the initial estimates for the failure data came from four main sources: (1) the manufacturer's specifications for off-the-shelf components, (2) a US military handbook on reliability prediction, (3) destructive testing of components by the manufacturer of the WEC and 4) the limited operational experience of the manufacturer. Additionally, as discussed in Section 2.2 of this article, data from other offshore domains (such as wind energy or the oil and gas sector) can be utilized. These domains have a longer history of reliability research and data collection, while still sharing a somewhat similar operating environment with WEC devices.

\subsection{MegaRoller OWSC Concept Development}

The research work on WEC reliability modelling presented in this article is related to an ongoing EU-funded research project, 'MegaRoller,' supporting the concept development of a 1 MW OWSC and the system design of an innovative power take-off system (PTO) that applies hydraulics. The overall goal of the MegaRoller project is to develop a new- 
generation oscillating wave surge converter based on the previous WaveRoller concept [23], which uses bottom-hinged panels to follow the surge movement of water in a nearshore area at a depth of 10-25 m [24]. The MegaRoller device consists of a foundation and a panel that is connected to two separate PTO systems. The PTOs first convert the rotational movement captured by the panel into linear movement. The linear movement is then converted into hydraulic energy, and hydraulic accumulators are used for energy storage. Finally, the hydraulic energy is converted into electricity and transferred to grid.

The MegaRoller project is an EU-funded research and innovation action for 2018-2021. The project is coordinated by Hydroll $\mathrm{Oy}$, and the project partners are AW-Energy Oy, ABB, Hydman Oy, K2 Management, WavEC, SINTEF, Universitetet i Bergen, Leibniz Institute for Neurobiology and VTT Technical Research Centre of Finland Ltd. The aim of this multidisciplinary research project is to create expertise in the area of PTO design and its control systems and to be able to develop solutions to reduce the levelized cost of energy (LCOE) to below $\$ 150$ per MWh for the future generations of OWSC devices [24]. In the project, VTT combines economic assessment and technical reliability assessment to supply input for the optimization of operational efficiency and reliability and minimize the life cycle costs of WEC concepts.

\subsection{Focus and Structure of This Article}

The three main contributions of this article are the following. Firstly, we describe and apply a reliability prediction approach based on reliability block diagrams to a novel hydraulic PTO system concept. Secondly, we describe the process and data sources for gathering reliability data for components used in the system, considering the very limited historical or experimental data available. This includes considerations of the data quality in various sources. Finally, we present selected examples of the reliability modelling case study, focusing on parts of the MegaRoller PTO system concept.

The article is structured as follows: Section 1 describes the background to wave energy and the OWSC system concept applying a hydraulic PTO. The previous efforts in reliability analyses of WECs available in the literature are described. Section 2 describes the materials and methods of this study, describing the constructive research and case study research approaches applied in this article and providing the theoretical background of the reliability block diagram method. Additionally, it describes the reliability data sources that were used in reliability calculations. Section 3 describes the results of the case study research applying the RBD-based methodology to the PTO system concept. In Section 4, we discuss the implications of the simulation results. Additionally, we discuss the applicability of the RBD-based approach in the development of a WEC PTO concept. The credibility of the achieved results based on the used reliability data sources is also evaluated.

\section{Materials and Methods}

In this study, the research work on reliability modelling and the analysis of the hydraulic PTO system followed a design science research approach [25]. More specifically, the study was planned according to the design-inclusive research approach [26]. This approach was chosen for this study because the exploration of new knowledge and theoretical explanations, as well as the utilization of systematic problem-solving techniques-the main elements of design science research - are also essential in the development of a reliability model for a new technology design. In the first phase of the study, the reliability model for the PTO system was defined and constructed using the reliability block diagram (RBD) modelling method. In the second phase, the reliability model was tested and evaluated with the relevant available data.

The design science research approach is a quite new approach for research activities aiming to explore new technologies and construct new objects, i.e., new technical systems [27]. The design-inclusive research approach has been further developed from the general design science research approach for studies that include actual creative design actions between explorative and confirmative research actions [26]. According to 
Horváth [26], the design inclusive research approach typically includes three phases: (1) exploration and definition of the problem, the context and setting hypothesis; (2) designing alternative solutions and testing the solutions; and (3) verification of the hypothesis, validation of the research and generalizing the results towards other applications.

\subsection{Reliability Modelling Method}

There are several methods for performing system reliability analyses. Some of the most widely used include fault tree and event tree analyses (FTA and ETA), as well as various Bayesian methods. In this study, we apply a reliability modelling approach based on the use of reliability block diagrams (RBDs). The reliability block diagram method is described in standard IEC 61078:2016 [28]. The RBD method was selected based on the following key characteristics of the method: RBD allows for reliability prediction based on the reliability of its components, which is suitable for this case, as most of the system structure and components were specified before the time that the modelling took place. RBD also operates in a success space (as opposed to Fault tree analysis, which focuses on individual failures), providing a suitable means for product development where individual failure modes are not the focus. Additionally, RBD provides a graphical representation of the system reliability structure, potentially providing a means for communicating reliability improvement needs between stakeholders involved in system design.

In an RBD analysis, the system's successful functioning is presented in a graphical manner. The system is presented as interconnected blocks, each representing a component of the system [28]. The blocks are assigned with a probability distribution representing each block's failure characteristics [29]. Most RBDs can be solved analytically, but especially for repairable systems or systems with dynamic features, a Monte Carlo simulation is often more efficient at performing the calculations. There is no limit to the size of the RBD; it can be focused on a certain part of the system or the entire system based on the need in system development.

In practice, RBD is used to describe the reliability structure of the system. From a reliability perspective, the components are in series or parallel configurations. As an example, in Figure 1, the two PTOs in the MegaRoller concept are in parallel configuration and the other components are in series configuration. For this study, only elements within the PTO system were modelled. Thus, the PTO system consists of several sub-diagrams.

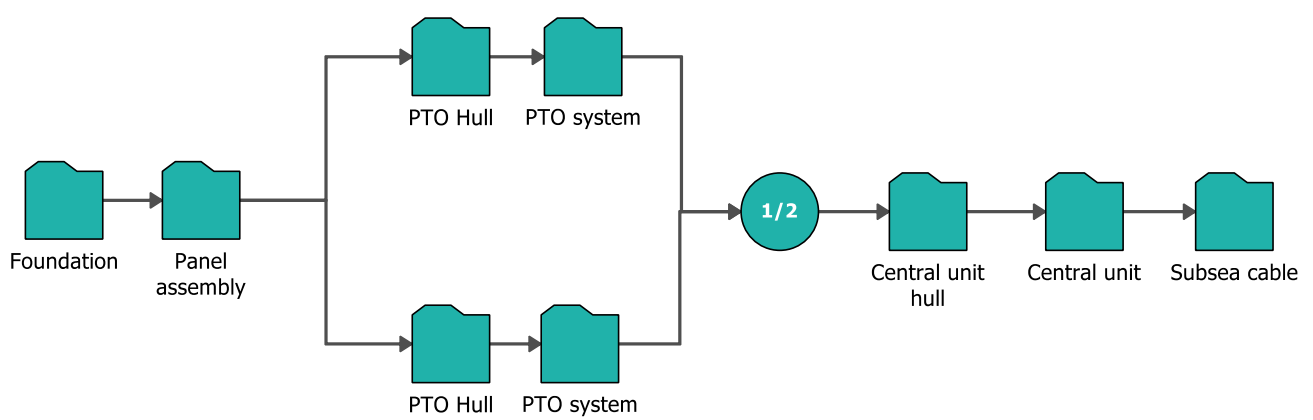

Figure 1. A reliability block diagram displaying the configuration of the MegaRoller concept, consisting of two PTOs and a central unit.

In a series configuration, the failure of any component will lead to the failure of the entire system. In the case of a series system consisting of independent components, the reliability of the entire system is given by the product of the individual component reliabilities, $\mathrm{R}_{\mathrm{i}}[30]$ :

$$
\mathrm{R}_{\mathrm{S}}=1-\prod_{\mathrm{i}=1}^{\mathrm{n}} \mathrm{R}_{\mathrm{i}}
$$

Another basic configuration is a parallel system. In a parallel system, the system remains functional if any one of the parallel components is functional. In addition, so- 
called $\mathrm{n}$ out of $\mathrm{k}$ configurations can also be represented, meaning that a certain number of parallel components are required for the system to remain operational. The reliability of a simple parallel system is given by [30]:

$$
\mathrm{R}_{\mathrm{S}}=1-\prod_{\mathrm{i}=1}^{\mathrm{n}}\left(1-\mathrm{R}_{\mathrm{i}}\right)
$$

For modelling the reliability performance of individual components, a probability distribution called a life distribution is used. Some of the most commonly used life distributions in reliability engineering include the Weibull distribution, lognormal, exponential, and normal distributions [31]. Other distributions can also be used depending on the component that is being studied. The model described in this article applies the Weibull and exponential distributions. In the following, these two distributions are described in more detail. The usage of these distributions in this study is described in Section 3.2.1.

The exponential distribution is one of the simplest life distributions. It corresponds to a constant failure rate (i.e., random failure behavior). Some, especially electronic, components display this kind of failure behavior, which can be modelled using the exponential distribution. Due to its simplicity, however, this distribution is applied sometimes for other component types as well. It is also useful when the component is expected to be used only for its useful life phase, i.e., it will be replaced before it enters its wear-out phase. Some data sources make such an assumption and thus provide a constant failure rate number that is suitable to be used with the exponential distribution. The probability density function (pdf) for one-parameter exponential distribution is given by [30]:

$$
f(t)=\lambda e^{-\lambda t}
$$

where:

$\lambda=$ Constant rate, in failures per unit of measurement, (e.g., failures per year)

$\lambda=1 / \mathrm{MTTF}$

MTTF $=$ mean time to failure

$t=$ operating time, life, or age, e.g., in years or hours.

The Weibull distribution is very widely used in reliability engineering as it is very flexible and can represent different types of failure behavior. By altering the parameters, it can be used to represent different parts of the so-called bathtub curve, i.e., infant mortality, random failures, as well as wear-outs. The distribution's pdf in its three-parameter form is defined as [30]:

$$
f(t)=\frac{\beta}{\eta}\left(\frac{t-\gamma}{\eta}\right)^{\beta-1} e^{-\left(\frac{t-\gamma}{\eta}\right)^{\beta}}
$$

where:

$t=$ operating time, life, or age, e.g., in years or cycles

The three parameters can be interpreted as follows:

$\beta=$ Shape parameter, which defines the shape of the distribution and thus has a distinct effect on the failure rate.

$\eta=$ Scale parameter, which is also known as the characteristic life. This parameter "stretches" the distribution, defining where the bulk of the distribution lies. It has the same unit as $t$.

$\gamma=$ Location parameter. This parameter shifts the distribution along the time axis. In many cases, it is not needed as the distribution can start at zero. Then, the distribution reduces to a simpler two-parameter Weibull form.

\subsection{Reliability Data Collection for WEC Technologies and Concepts}

To utilize the probability distributions for developing a new system and assessing its reliability, a significant amount of data is already required for calculating the system's reliability level in the early stages of the development process. In many cases, there are 
previous generations of similar systems with service and history data that can be utilized by condition monitoring systems (CMS) and supervisory control and data acquisition systems (SCADA) as a source of information. Concerning WECs, the situation is more challenging, because there is generally no field data available and because the solutions used to capture wave energy differ a lot from each other.

Field data might exist on some of the components used in WEC, but as the usage profile of the components in WEC may differ from the usage described in the field data from other industries, the validity of data for calculating WEC reliability estimations needs to be carefully considered. For example, the floating variants of WECs will face different loads from the environment compared with those that are submerged and utilize the surge phenomena, such as the MegaRoller concept.

Since no WEC-specific reliability databases are available, relevant data from other industries was studied to support reliability analysis. As an established offshore renewable energy industry, the wind energy sector is one of the most relevant sources of data for consideration when studying WEC reliability. Unlike in WECs, the technical solutions of wind turbines are quite similar between different vendors, even though the turbine designs still change because of technological advancement [32]. Several initiatives have started to gather data on the performance and reliability of wind turbines [33]. The largest databases related to wind turbine data are Windstats (data from Germany and Denmark), WMEP (Germany) and CIRCE (Spain), in which data from several thousands of turbines over periods of more than 5 years has been collected [34]. As an example, some indicators that have been used to describe the reliability of wind turbines are [33]:

- The capacity factor $(\mathrm{CF})$ : the ratio of the turbines' actual power output over a period of time to its theoretical power output.

- Time-based availability (At): the share of time where a wind turbine (WT) is operating or able to operate in comparison to the total time.

- Technical availability (Atech): the share of time where a WT is available from a technical perspective.

- Energetic availability (Aw): the turbines' energy yield compared with the potential output, which highlights long down times during high wind speed phases and reduced operation.

- Failure rate $(\lambda)$ : the probability of a system failing within a specific period of time.

- Mean time to failure (MTTF): $1 / \lambda$, if the failure rate is constant.

- Mean time between failures (MTBF): for repairable systems, this also includes downtime due to repair.

- Mean downtime: expected or average downtime after a system fails and stops operation.

In practice, all these indicators can be used to assess the reliability of WECs as well. The focus of this study was on the technical reliability of the system, i.e., on the failure probability over the intended periodic maintenance interval of the MegaRoller device. Thus, the effects of possible corrective maintenance or considerations on the power output were excluded from the calculations.

The distribution of the reliability data significantly influences the calculated reliability estimations. Changing the failure distribution can alter the results by up to $20 \%$, and therefore it is essential to know how the failures are distributed around the mean value [32]. The failure rates used in the calculations are not constant throughout the lifetime of wind turbines, but this simplification is commonly used [32].

In addition to wind power, another relevant field in which reliability data have been widely collected is the offshore oil and gas industry. In this field, reliability data are available, for example, from the offshore reliability database OREDA Cloud 2020 [35]. In OREDA, the data are divided into topside and subsea components, with topside components above and subsea components below the waterline. Even though the MegaRoller device is submerged during operation, the components of the PTO are inside a watertight hull and not in direct contact with seawater. Thus, the usage of the topside component data can be justified. The environmental conditions of the PTO components are also controlled: 
the environment is dry and pollution free, and the temperature changes are slow because of the balancing effect of the seawater outside the hull. Therefore, the selection of optimistic component reliability estimations instead of mean values is justified when using data provided by OREDA.

Since most of the PTO system components are commercial off-the-shelf items, data from the manufacturers' datasheets can be utilized. Even the tailor-made components in the system can reach some initial estimates of the reliability level by comparing them with the manufacturers' other similar components and data according to the use cycles and load rates. However, the challenge is how to express the point estimate given by the manufacturer or in a datasheet as a life distribution in the most realistic way.

In cases where databases or manufacturer-provided data are not available, one possibility is to use functional safety standardization as support. For example, the standard ISO 13849-1:2015 [36] provides generic MTTF values for certain components to be used in calculations. These values, however, are intended for functional safety calculations and can thus be conservative for reliability engineering purposes.

\section{Results}

\subsection{Modelling Process}

The system reliability modelling process applied in this study is presented in Figure 2. The first step, like in any analysis, is to define the analysis purpose and the limits of the system that is to be analyzed. In this study, modelling was limited to the MegaRoller PTO, and all elements of the device outside the PTO were considered as items that cannot fail. The physical hull of the PTO was also considered as a cannot fail item. Another important definition in RBD modelling is to specify the system success (and failure) criteria. In the case of this analysis, a certain level of degradation in power production capability was considered acceptable, i.e., the device was still considered operational, even if a defined amount of the power production capacity was lost.

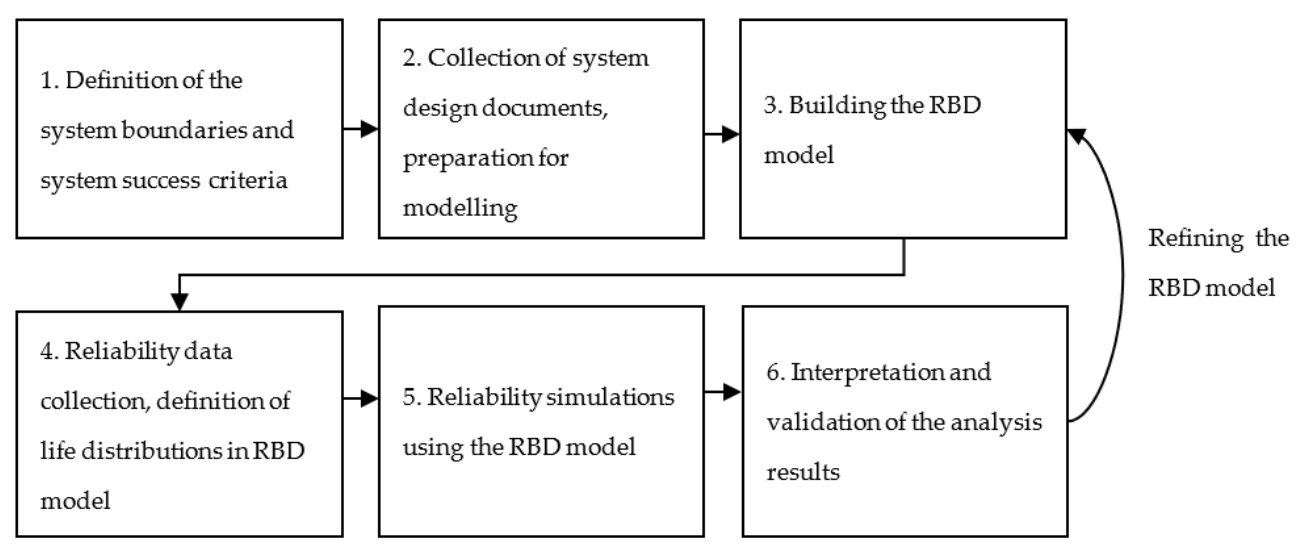

Figure 2. Reliability modelling process applied in this study.

The second step of the analysis was to gather the system design documentation relevant for modelling and analysis purposes. The documentation included hydraulic and electrical design drawings of the PTO system, accompanied by corresponding component listings with detailed component specifications. This also included some information on the component loading characteristics relevant for reliability, specifically usage hours and the numbers of cycles for components that are not in continuous use or are subject to a cyclical usage profile. In addition, information from previous functional failure mode effects and criticality analysis (FMECA) was used to support the modelling by providing knowledge on the key system functions.

The actual RBD model was constructed based on design documentation with the support of system designers. The design documentation included technical drawings of the PTO, component lists, and information on the usage profiles of the system components. 
BlockSim 2018 (ReliaSoft, Tucson, AZ, USA) software was used to construct the model. The software provides a graphical interface for creating the RBD model as well as simulation capabilities for performing the calculations [37]. The PTO was first modelled at a high level to describe the key system elements. Sub-diagrams were then used to structure the model and to model each of the subsystems. At the most detailed level, the individual components were modelled. The characteristics of the reliability model, as well as the life distributions used for various component types, are described in more detail in Section 3.2. The reliability data collection, also described in more detail in other sections of this article, was performed partly simultaneously with the actual RBD modelling.

The results of the RBD model were calculated in BlockSim software by running Monte Carlo simulations. Monte Carlo simulations were applied instead of analytical calculations because the number of system components was too high to feasibly calculate purely analytical results. The simulation approach also provides additional flexibility by allowing later expansion of the reliability model to consider other relevant system characteristics, such as maintenance scheduling aspects [38].

\subsection{RBD Model Structure and Characteristics}

The key functions and related technical systems of the MegaRoller concept are described in Figure 3. The RBD model was developed so that it included the elements with a white background in the figure, as these are considered parts of the PTO system. The PTO system model consists of several hundred components, but many of these are duplicates or share similar reliability characteristics. Thus, the number of actual different component types in terms of life distributions is much lower.

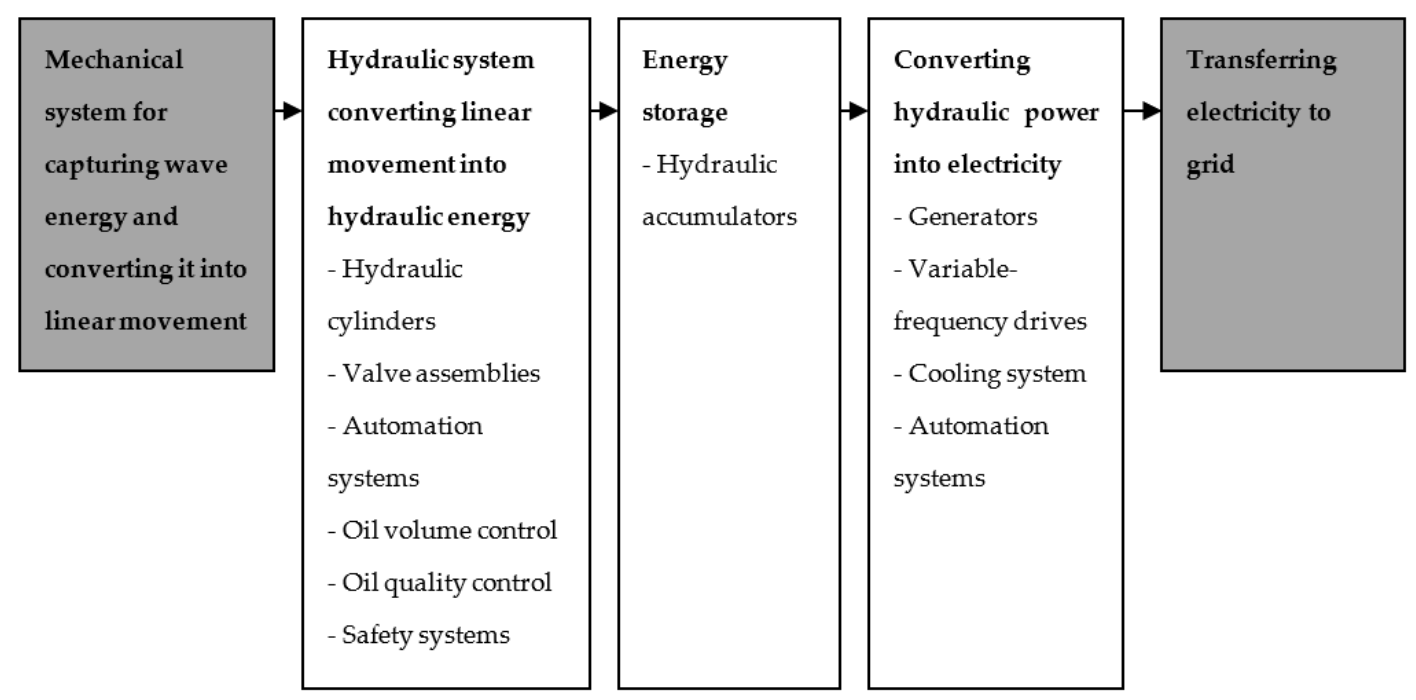

Figure 3. A simplified overview of the device functions, key systems, and component types associated with the functions. The functions with a gray background are outside the PTO system and are thus excluded from the RBD model.

\subsubsection{Component Types and Life Distributions}

Table 1 presents some of the key component types in the system, as well as the life distributions applied to these component types. The table also includes comments on why the specific distribution was chosen and which data sources were used to define the distribution parameters.

Generally, for equipment with rotating parts (such as electric motors and generators), bearing failure caused by wear was considered the most probable failure mode. A 2parameter Weibull distribution was selected to model this kind of failure behavior. For the shape parameter $\beta$, a typical value for rotating equipment provided by GE [39], was applied, and the scale parameter $\eta$ was determined based on databases and manufacturer specifications based on availability. For hydraulic cylinders and accumulators, both being 
essentially piston-type components, the main failure mode considered was sealing failure due to wear. Thus, a two-parameter Weibull was utilized for them as well, with parameters from the manufacturers and research literature [40].

When compared with mechanical components that are mostly subject to wear-related failures, electrical equipment and automation system components often display a more random failure behavior. Valves with electronic control were considered from this perspective as well. A one-parameter exponential distribution was selected to represent these components. The failure rate for most of these components was obtained from manufacturers' datasheets.

Table 1. Examples of important component types considered in the RBD model and the life distributions that were used to model the reliability characteristics of different components. The source and reasoning for the selection of the distributions are described in the comments column.

\begin{tabular}{|c|c|c|}
\hline Component Type & Life Distribution & Comments \\
\hline $\begin{array}{c}\text { Automation products } \\
\text { (processor modules, I/O } \\
\text { modules, communication } \\
\text { modules, etc.) }\end{array}$ & 1-parameter Exponential & $\begin{array}{l}\text { MTTF data available from } \\
\text { manufacturers. }\end{array}$ \\
\hline Contactors & 1-parameter Exponential & - “- \\
\hline Electric generators & 2-parameter Weibull & $\begin{array}{c}\text { Rotating machinery (the main } \\
\text { failure mechanism is bearing } \\
\text { wear). Data from OREDA } \\
\text { database [35]. }\end{array}$ \\
\hline Electric motors & 2-parameter Weibull & - " - \\
\hline Hydraulic accumulators & 2-parameter Weibull & $\begin{array}{c}\text { Piston-type device (the main } \\
\text { failure mechanism is sealing } \\
\text { wear). Data from } \\
\text { manufacturer. }\end{array}$ \\
\hline Hydraulic cylinders & 2-parameter Weibull & $\begin{array}{c}\text { Piston-type device. Data from } \\
\text { literature [40]. }\end{array}$ \\
\hline Hydraulic motors & 2-parameter Weibull & $\begin{array}{l}\text { Rotating machinery. Data } \\
\text { from OREDA database [35]. }\end{array}$ \\
\hline Hydraulic pumps & 2-parameter Weibull & —- "— \\
\hline Relays & 1-parameter Exponential & $\begin{array}{l}\text { MTTF data available from } \\
\text { manufacturers. }\end{array}$ \\
\hline Valves (electronic control) & 1-parameter Exponential & $\begin{array}{c}\text { Main failure mechanism is } \\
\text { failure of the electronic } \\
\text { control. MTTF from ISO } \\
\text { 13849-1:2015. }\end{array}$ \\
\hline Variable-frequency drives & 1-parameter Exponential & $\begin{array}{l}\text { MTTF data available from } \\
\text { manufacturers. }\end{array}$ \\
\hline
\end{tabular}

\subsubsection{Case Example}

Figures 4 and 5 provide an illustrative example of a part of the reliability-centered system development approach applied in this project. The example focuses on a subsystem of the PTO that is related to control of high-pressure hydraulic accumulators. Due to confidentiality considerations related to new technology development, the data, component types and component configuration presented here are for illustrative purposes only and are not representative of the actual MegaRoller system design. However, for the entire MegaRoller PTO concept, similar calculations were performed as described in the examples below, and the discussion and conclusions of this article are based on the complete PTO system model. 


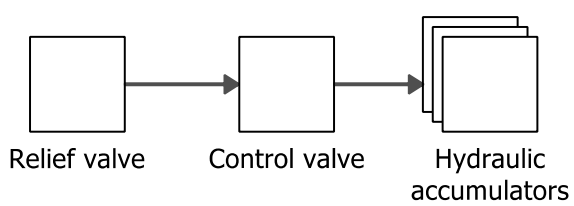

(a)

\begin{tabular}{|l|r|}
\hline \multicolumn{2}{|c|}{ Block Failure Criticality Ranking } \\
\hline \multicolumn{1}{|c|}{ Block Name } & \multicolumn{1}{c|}{ RS FCI } \\
\hline Control valve & $77,71 \%$ \\
\hline Relief valve & $22,17 \%$ \\
\hline Hydraulic accumulators & $0,12 \%$ \\
\hline
\end{tabular}

(b)

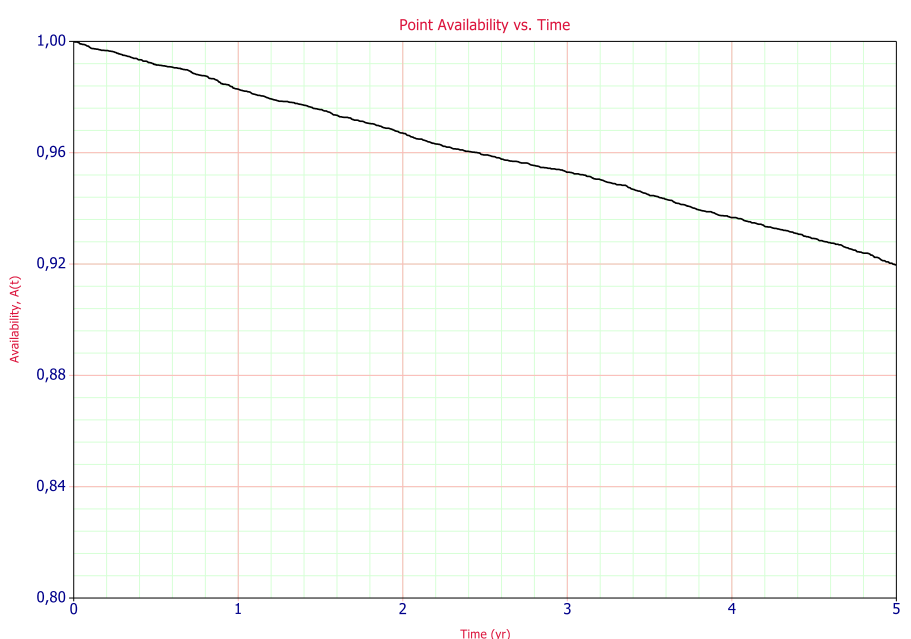

(c)

Figure 4. RBD model of the example system (a), the failure criticality index (FCI) calculation of subsystem components (b), and a plot of the system availability over time (i.e., probability that the system is available at a given point of time) (c).

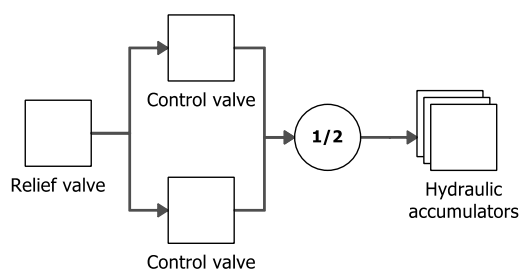

(a)

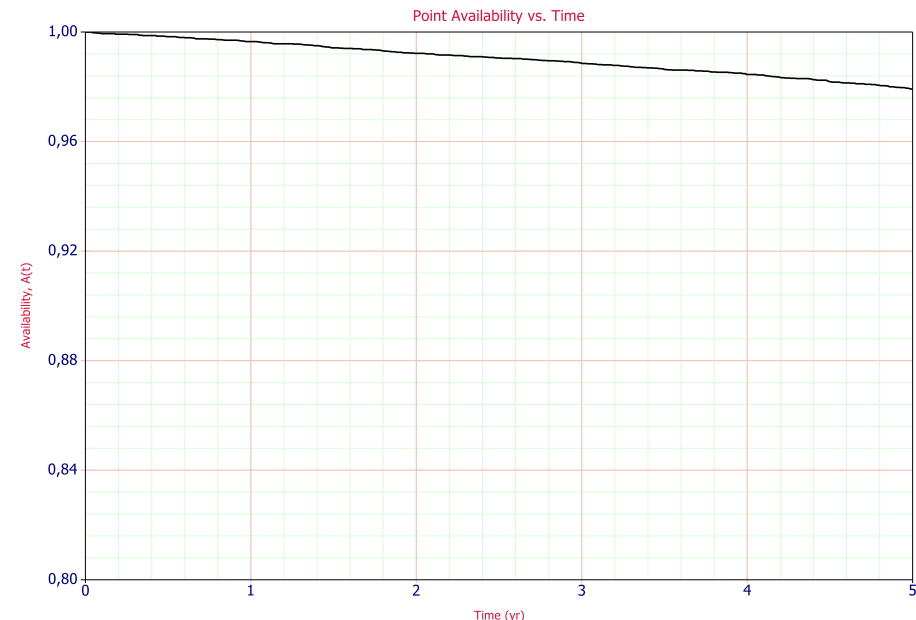

(b)

Figure 5. RBD model of the modified example system design (a) and a plot of the improved system availability performance over time (b).

The subsystem presented in Figure 4 includes the RBD representation of a subsystem design with hydraulic accumulators, a control valve and a relief valve. All components in the subsystem were assigned reliability distributions as per Table 1, i.e., the valves had a one-parameter exponential distribution, with a relief valve with a slightly longer expected lifetime due to the different profiles of use. The accumulators are represented as a multiblock, which represents an assembly of several accumulators in a parallel configuration, with a pre-defined threshold value for the number of components that are allowed to fail so that the entire system still remains functional. The accumulators apply a two-parameter Weibull model.

In addition to the RBD configuration, Figure 4 shows the simulation plot of the system availability performance over a 5-year period, based on 10,000 Monte Carlo simulation runs in the BlockSim 2018 (ReliaSoft, Tucson, AZ, USA) software. Additionally, block failure criticality ranking calculation results are shown. The failure criticality index (FCI) represents the percentage of simulation runs where the component triggered the system failure [41]. The availability plot can be used to visualize the system reliability performance over time and to determine whether the system fulfils the design goals that have been assigned to it. 
The criticality ranking, on the other hand, can be used to direct reliability improvement efforts to the components where the largest impact on overall system reliability can be obtained. Similar analyses can be applied to the entire PTO to identify the most critical subsystems and components.

The main methods used for reliability improvement include component choice and redundancy. Component choice simply means that components with a better reliability performance are selected. In this example case, it was expected that high-quality components were already used, leaving very little room for improvement with simple component changes. The system reliability performance can, however, be improved by adding redundancy to the control valves, which was identified as the most reliability-critical component. Figure 5 shows an alternate system design applying the same components as before but with added redundancy for the control valves. The system availability plot shows a significant increase in the reliability performance.

\section{Discussion}

In addition to providing quantitative results similar to those described in the case study examples above, a reliability model of a system can also be used to illustrate and comprehend the relations between subsystems and components. For quantitative results, however, utilization of the model also requires relevant input data for calculations. This was identified as a major challenge in WEC development, where only very limited historical data are available. For some applications, e.g., wind turbines, there are a lot of data available, gathered by multiple entities. As the basic structure of wind turbines is quite similar, the data can be utilized for reliability estimations, even though the design details differ from each other. For wave energy converters like MegaRoller, the general design is unique, and there are no other solutions that can be directly compared to it. In addition, the loads caused by the natural conditions of the system add to the complexity of reliability estimations. In this case, the only sources of information were the testing data generated by the company itself and the general data available from component manufacturer's datasheets and in commercially available reliability databases.

The manufacturers' datasheets usually provide only basic information about the reliability performance of the component or device. In practice, the mean time to failure (MTTF) is a typical reliability key figure that is provided in datasheets. This value can be connected, for example, to the operating temperature; the MTTF value varies depending on the temperature range the system is operating in. Calculating the reliability with a reliability model using a single value is not possible in this way. The analyst should estimate what the failure distribution curve looks like around the given time. This requires expertise on the failure behavior of different component types. With electrical components the failure behavior near the MTTF time is typically random; some units survive longer than others. For sealing rings and other disposables, the MTTF describes the time when most of the population fails, but only a few of them fail before the MTTF, and some can operate for a long time after the MTTF. For example, for hydraulic cylinders the seals first settle down to the typical operating length of the piston, and after the breaking-in period, the wear is minimal for a long time. Of course, the reliability of hydraulic components is highly dependent on the purity of the hydraulic fluid.

In commercially available reliability databases such as OREDA, there are reliability estimates available for hundreds of different components. In OREDA, the data are gathered from the very harsh conditions of the offshore oil and gas industry. Therefore, the reliability numbers can be rather pessimistic when utilizing the data in the MegaRoller calculations. In the MegaRoller, the PTO is covered with a watertight hull, and inside it the conditions are quite stable compared with the conditions on the surface or in direct contact with seawater. OREDA and other similar databases offer not only a single point value for the reliability but also some other key descriptive figures, so it is possible to select more representative values for the model, e.g., if the given mean value cannot be justified as such. 
Machine systems, such as the MegaRoller, are built from several thousands of individual components. Making a highly detailed model that contains all the components is very laborious. Analysts should use their expertise to justify which components are relevant to the model and which are not. In hydraulic systems, there can be hundreds of fittings and pipes, and in electrical systems, there are a considerable number of connectors and component bases. Usually, these components do not cause any specific risk to the system reliability, and they can be left out of the modelling. By concentrating on the components that are directly related to the functions of the system or on the ones that clearly deteriorate with age, the modelling phase can be shortened significantly.

In this study, the reliability analysis approach based on RBD modelling was successfully applied to the MegaRoller PTO concept. In general, despite the challenges in data acquisition presented in this article, the reliability modelling approach applying RBDs was found to be useful in supporting system development. The main outputs of the analysis were the following:

- Prediction of the failure probability of the PTO system during the intended periodic maintenance interval. This information can be used, for example, to further develop the scheduling of periodic maintenance activities to optimize the economic efficiency of the system.

- A listing of the most-reliability-critical components in the PTO system. This can be used to focus real-world testing of the device and to support future design efforts if further efforts to increase the system reliability are necessary.

- A visual representation of the PTO system reliability structure, which can be easily modified to compare various future design choices in terms of reliability performance.

In the next steps of system development, a test facility is established to provide experimental data, based on which the model can be further refined. As for future work, the reliability modelling approach can also be expanded to cover further aspects, such as considerations of maintenance activities. Additionally, other parts of the WEC, which are outside the PTO, could be added for a more comprehensive device-level analysis. This could be further extended to cover wave farm-level considerations to compare different installations of several MegaRoller devices.

Author Contributions: Conceptualization, E.H., T.V. and R.T.; methodology, R.T., M.R. and E.H.; formal analysis, E.H. and T.V.; investigation, E.H., T.V. and J.S.; data curation, T.V.; writing-original draft preparation, E.H., T.V., R.T. and J.S.; writing-review and editing, E.H., T.V., R.T., J.S. and M.R.; visualization, E.H.; supervision, E.H.; project administration, R.T.; funding acquisition, R.T. All authors have read and agreed to the published version of the manuscript.

Funding: This project has received funding from the European Union's Horizon 2020 research and innovation programme under grant agreement No 763959.

Conflicts of Interest: The authors declare no conflict of interest.

\section{References}

1. Ocean Energy Europe (OEE). Available online: https://www.oceanenergy-europe.eu (accessed on 2 March 2021).

2. European Commission Strategic Energy Technologies Information System (SETIS). Ocean Energy. Available online: https: //setis.ec.europa.eu/system/files/Technology_Information_Sheet_Ocean_Energy.pdf (accessed on 2 March 2021).

3. Ocean Energy Europe (OEE). Wave Energy. Available online: https: / /www.oceanenergy-europe.eu/ocean-energy / wave-energy / (accessed on 2 March 2021).

4. International Renewable Energy Agency (IRENA). Ocean energy. Available online: https://www.irena.org/ocean (accessed on 2 March 2021).

5. International Renewable Energy Agency (IRENA). Wave Energy Technology Brief; IRENA: Abu Dhabi, United Arab Emirates, 2014.

6. The European Marine Energy Centre Ltd. Wave Devices. Available online: http://www.emec.org.uk/marine-energy/wavedevices/ (accessed on 2 March 2021).

7. Gunawardane, S.D.G.S.P.; Folley, M.; Kankanamge, C.J. Analysis of the hydrodynamics of four different oscillating wave surge converter concepts. Renew. Energy 2019, 130, 843-852. [CrossRef]

8. Têtu, A. Power Take-Off Systems for WECs. In Handbook of Ocean Wave Energy. Ocean Engineering E Oceanography; Pecher, A., Kofoed, J., Eds.; Springer: Cham, Switzerland, 2017; Volume 7. 
9. Kofoed, J. The Wave Energy Sector. In Handbook of Ocean Wave Energy. Ocean Engineering E Oceanography; Pecher, A., Kofoed, J., Eds.; Springer: Cham, Switzerland, 2017; Volume 7.

10. Wolfram, J. On Assessing the Reliability and Availability of Marine Energy Converters: The Problems of a New Technology. Proc. Inst. Eng. Part J. Risk Reliab. 2006, 220, 55-68. [CrossRef]

11. Ambühl, S. Reliability of Wave Energy Converters. Ph.D. Thesis, Aalborg University, Aalborg, Denmark, 2015.

12. Ransley, E.J. Survivability of Wave Energy Converter and Mooring Coupled System using CFD. Ph.D. Thesis, University of Plymouth, Plymouth, UK, 2015.

13. Coe, R.G.; Neary, V.S. Review of Methods for Modeling Wave Energy Converter Survival in Extreme Sea States. In Proceedings of the 2nd Marine Energy Technology Symposium (METS2014), Seattle, WA, USA, 15-17 April 2014.

14. O'Brien, L.; Christodoulides, P.; Renzi, E.; Stefanakis, T.; Dias, F. Will oscillating wave surge converters survive tsunamis? Theor. Appl. Mech. Lett. 2015, 5, 160-166. [CrossRef]

15. Cretu, A.; Munteanu, R.; Iudean, D.; Vladareanu, V.; Karaisas, P. Reliability assessment of linear generator type wave energy converters. In Proceedings of the 2016 International Conference on Applied and Theoretical Electricity, ICATE 2016-Proceedings, Craiova, Romania, 6-8 October 2016.

16. Mueller, M.; Lopez, R.; McDonald, A.; Jimmy, G. Reliability analysis of wave energy converters. In Proceedings of the 2016 IEEE International Conference on Renewable Energy Research and Applications, ICRERA 2016, Birmingham, UK, 20-23 November 2016; pp. 667-672.

17. Thies, P.R. Advancing Reliability Information for Wave Energy Converters. Ph.D. Thesis, University of Exeter, Exeter, UK, 2012.

18. Henderson, R. Design, simulation, and testing of a novel hydraulic power take-off system for the Pelamis wave energy converter. Renew. Energy 2006, 31, 271-283. [CrossRef]

19. McAuliffe, F.D.; Macadré, L.-M.; Donovan, M.H.; Murphy, J.; Lynch, K. Economic and Reliability Assessment of a Combined Marine Renewable Energy Platform. In Proceedings of the 11th European Wave and Tidal Energy Conference, Nantes, France, 6-11 September 2015; p. 10.

20. Heikkilä, E.; Sarsama, J.; Välisalo, T.; Räikkönen, M.; Tiusanen, R. Reliability-centered Development of a Wave Energy Converter: Interfaces between Reliability Modeling, FMECA and LCC. In Proceedings of the 2019 World Congress: Resilience, Reliability and Asset Management: Conference Proceedings, Singapore, 28-31 July 2019; pp. 248-251.

21. Tiusanen, R.; Heikkilä, E.; Räikkönen, M.; Välisalo, T. System Approach to Reliability Engineering-Case: Wave Energy Converter. In Proceedings of the 30th European Safety and Reliability Conference and the 15th Probabilistic Safety Assessment and Management Conference (ESREL2020 PSAM15), Venice, Italy, 1-5 November 2020.

22. Gray, A.; Dickens, B.; Bruce, T.; Ashton, I.; Johanning, L. Reliability and O\&M sensitivity analysis as a consequence of site specific characteristics for wave energy converters. Ocean Eng. 2017, 141, 493-511.

23. AW-Energy Website on WaveRoller Technology. Available online: http://aw-energy.com/waveroller/\#technology (accessed on 3 March 2021).

24. MegaRoller Project Website. Available online: https:/ /www.sintef.no/projectweb/megaroller/ (accessed on 3 March 2021).

25. Reubens, R. To craft, by design, for sustainability: Towards holistic sustainability design for developing-country enterprises. Ph.D. Thesis, Delft University of Technology, Delft, The Netherlands, 2016.

26. Horváth, I. Comparison of three methodological approaches of design research. In Proceedings of the DS 42: Proceedings of ICED 2007, the 16th International Conference on Engineering Design, Paris, France, 28-31 July 2007.

27. Iivari, J.; Venable, J. Action research and design science research-Seemingly similar but decisively dissimilar. In Proceedings of the ECIS 2009 Proceedings, 2009; Available online: https:/ / core.ac.uk/download/pdf/301355252.pdf (accessed on 3 March 2021).

28. IEC 61078:2016. Reliability block diagrams. Available online: https://webstore.iec.ch/publication/25647 (accessed on 3 March 2021).

29. Čepin, M. Reliability Block Diagram. In Assessment of Power System Reliability; Springer: London, UK, 2011.

30. Relia Soft Corporation. System Analysis Reference. Available online: http://reliawiki.org/index.php/System_Analysis_ Reference (accessed on 3 March 2021).

31. O'Connor, A.; Modarres, M.; Mosleh, A. Probability Distributions Used in Reliability Engineering; Center for Reliability Engineering University of Maryland: College Park, MD, USA, 2016.

32. Scheu, M.N.; Kolios, A.; Fischer, T.; Brennan, F. Influence of statistical uncertainty of component reliability estimations on offshore wind farm availability. Reliab. Eng. Syst. Saf. 2017, 168, 28-39. [CrossRef]

33. Pfaffel, S.; Faulstich, S.; Rohrig, K. Performance and Reliability of Wind Turbines: A Review. Energies 2017, 10, 1904. [CrossRef]

34. Dao, C.; Kazemtabrizi, B.; Crabtree, C. Wind turbine reliability data review and impacts on levelised cost of energy. Wind Energy 2019, 22, 1848-1871. [CrossRef]

35. OREDA Cloud Database; Sintef: Trondheim, Norway, 2020.

36. ISO 13849-1:2015. Safety of Machinery. Safety-Related Parts of Control Systems. Part 1: General Principles for Design. Available online: https:/ / www.iso.org/standard/69883.html (accessed on 3 March 2021).

37. Relia Soft Corporation. 2015. BlockSim Features Overview. Available online: http://help.synthesisplatform.net/blocksim_reno9 /introduction_to_blocksim.htm (accessed on 11 May 2021).

38. Marquez, A.C.; Heguedas, A.S.; Iung, B. Monte Carlo-based assessment of system availability. A case study for cogeneration plants. Reliab. Eng. Syst. Saf. 2005, 88, 273-289. [CrossRef] 
39. General Electric Company. About Weibull Distribution. 2018. Available online: https://www.ge.com/digital/documentation/ meridium/Help/V43050/Default/Subsystems/ReliabilityAnalytics/Content/WeibullDistrubution.htm (accessed

on 3 March 2021).

40. Jocanović, M.; Šević, D.; Karanović, V.; Beker, I.; Dudić, S. Increased efficiency of hydraulic systems through reliability theory and monitoring of system operating parameters. Stroj. Vestn. J. Mech. Eng. 2012, 58. [CrossRef]

41. Wang, W.; Loman, J.; Vassiliou, P. Reliability importance of components in a complex system. In Proceedings of the Annual Reliability and Maintainability Symposium, Los Angeles, CA, USA, 26-29 January 2004; pp. 6-11. 